\title{
Locus of Control, Psychopathological Symptoms and Superstitious Beliefs
}

\section{Fatemeh Mohammad Hasan Naghash ${ }^{1, *}$, Mehrnaz Ahmadi Moarakeh²}

${ }^{1}$ M.A. Student of Clinical Psychology, Islamic Azad University, South Tehran, Iran

${ }^{2}$ Assistant Professor, Department of Clinical Psychology Islamic Azad University, South Tehran, Iran

\section{ARTICLE INFO}

\section{Article History}

Received: 11 August 2019

Revised: 13 January 2020

Accepted: 13 January 2020

Available online: February 2021

Article Type

Research Article

Keywords

Locus of control; Psychopathological

symptoms; Superstitious beliefs

\section{Corresponding Author*}

Fatemeh Mohammad Hassan Naghash received her master's degree in clinical psychology from the Faculty of Psychology and Educational Sciences, Islamic Azad University, South Tehran. Currently, he is working as a consultant and therapist for clinical disorders and lecturer of psychological injuries.

To correspond about this article, contact the Department of Clinical Psychology, Faculty of Psychology and Educational Sciences, Islamic Azad University, South Tehran Branch, Damavand St., next to Bouali Hospital, No. 4492, Postal Code 17117-34353.

ORCID: 0000-0002-0218-5614

E-mail: st_f_naghash@azad.ac.ir

doi: http://dx.doi.org/10.29252/bjcp.14.2.73

\section{ABSTRACT}

The purpose of this study was to investigate the relationship between locus of control and Psychopathological symptoms with superstitious beliefs.

The Research Project was descriptive correlational. The statistical population consisted of all female members in Tehran's neighborhood centers. In a clustered and accessible sampling method, 220 individuals were selected. The Internality, Powerful Others and Chance Scale (Levenson, 1981), Check List-90-Revised Scale (Derogatis, Rickels \& Rock, 1976) and The Measurement of Attitudes Related toThe Superstitious Beliefs (Acar, 2014) were used. Data were analyzed in descriptive and inferential statistics.

Findings indicate that superstitious beliefs has no significant relation with the subscale of internality locus of control. There is a significant direct relationship between the superstitious beliefs and external locus of control with the subscales related to the chances of being affiliated with the powerful others. Also, the subscale of being dependent on chance alone can explain $3 \%$ of the variance in superstitious beliefs positively. There is a direct and significant relationship between superstitious beliefs and all dimensions of morbidity symptoms, which explain $15 \%$ of the variance in superstitious beliefs. Also, depression symptoms alone can explain $3 \%$ of the variance in superstitious beliefs positively

Citation: Mohammad Hasan Naghash, F., \& Ahmadi, M. (1399/2021). Locus of Control, Psychopathological Symptoms and Superstitious Beliefs. Contemporary Psychology, 14(2), 71-80. http://dx.doi.org/ 10.29252/bjcp.14.2.73 


\section{مسند مهار كرى، نشانهاى مرضى و باور هاى خر افى}

\section{فاطمه محمدحسن نقاش '“"، مهرناز احمدى مبار كه'}

' ' دانشجوى ارشد روانشناسى بالينى، دانشعاه آزاد اسلامى، تهران جنوب، ايران

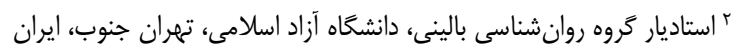

هدف يزوهش حاضر بررسى رابطهى مسندمهارگرى و نشانههاى مرضى با باورهاى خرافى بود.

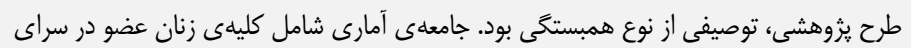

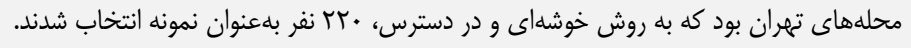

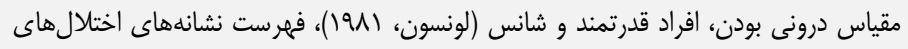

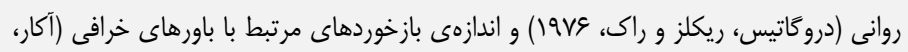

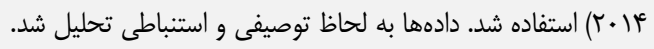

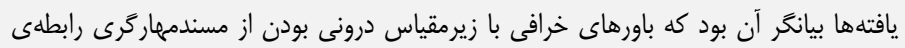

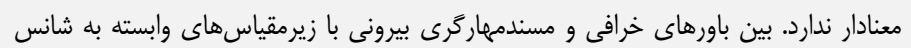

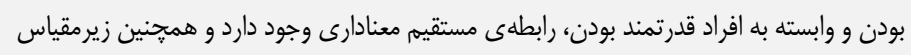

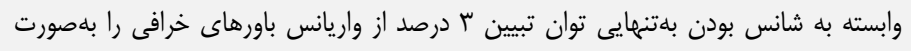

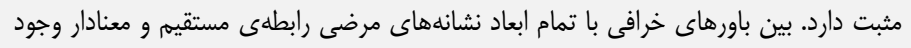

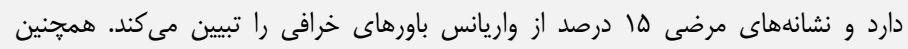

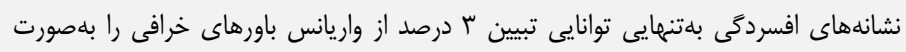
مثبت دارد.

بيشترين مراجعات در مواردى مانند مشكلات باردارى، زايمان،

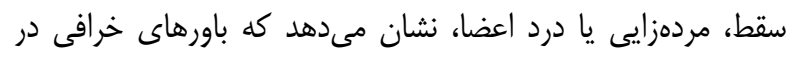

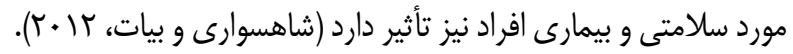

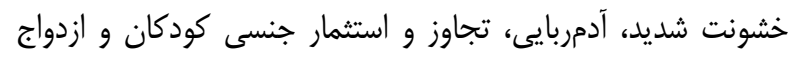

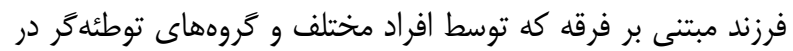
جمهورى دموكراتيك كنكو از طريق طلسم و باورهاى خرافى انجام فرام

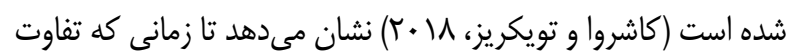

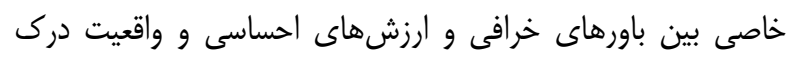

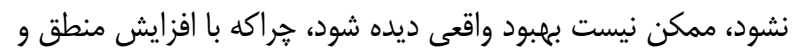

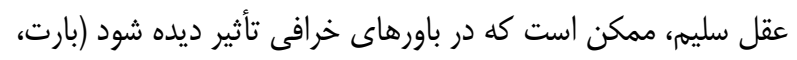

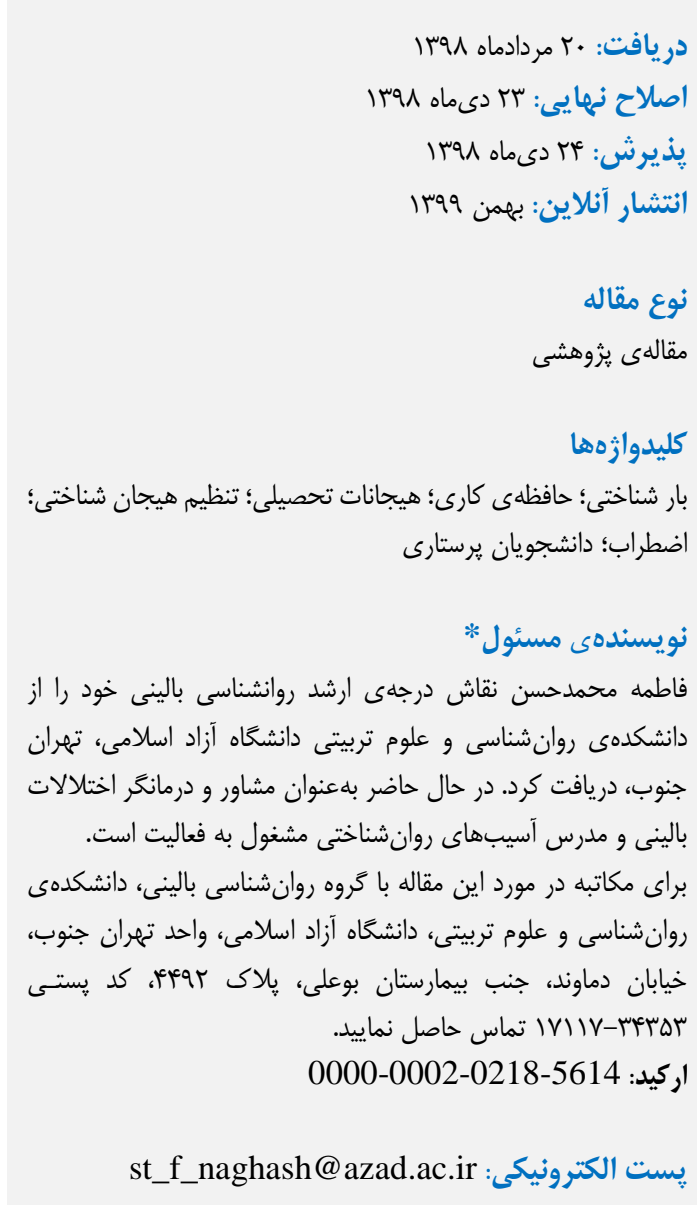

مقلدمه

در طول دهلهاى كذشته، يزوهشهاى زيادى در مورد باورهاى

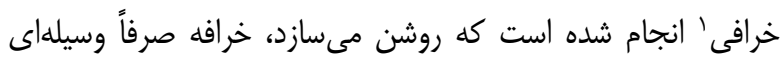

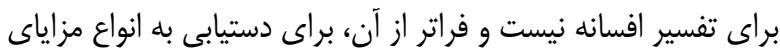

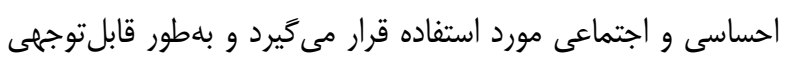

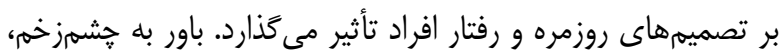

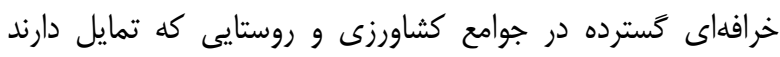

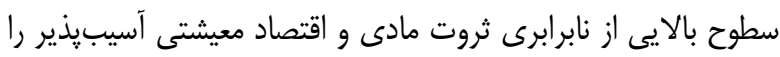

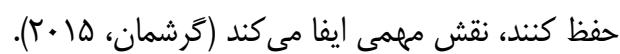


عضوى و نارساكنشورى فيزيولوزى است تلقى نمىشوند بلكه

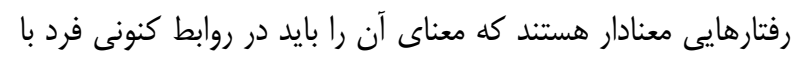

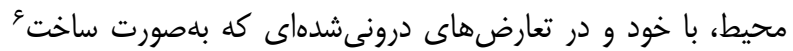

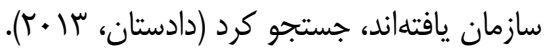

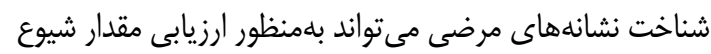

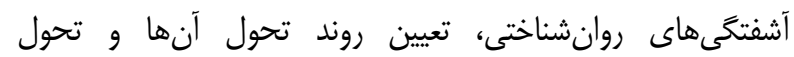

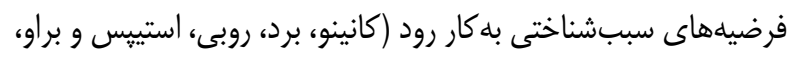

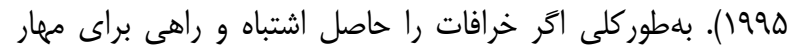

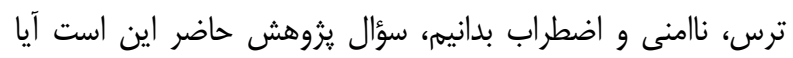

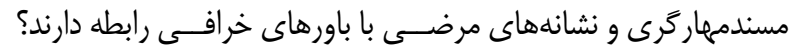

\section{روش}

طرح بُومشى

طرح يزوهشى مطالعلى حاضر توصيفى از نوع همبستخى بود.

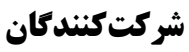

جامعلى آمارى در اين يزوهش زنان عضو در سراى محلههاى

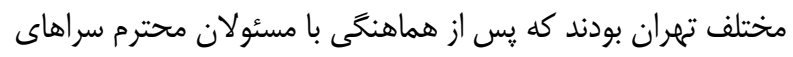

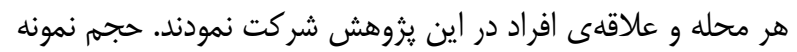

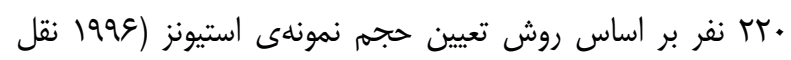

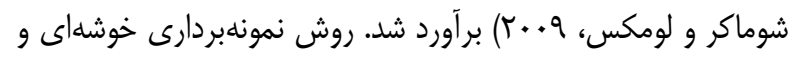

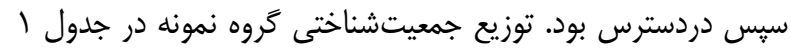

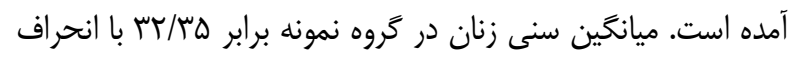

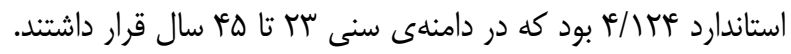

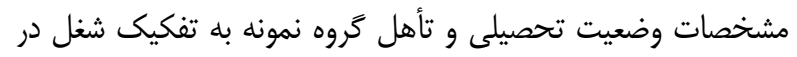

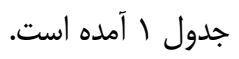

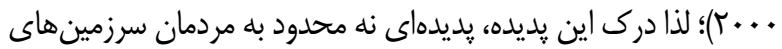

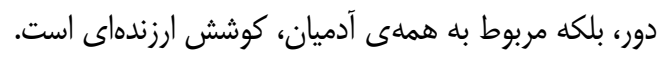

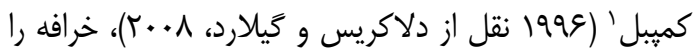

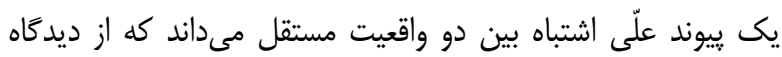

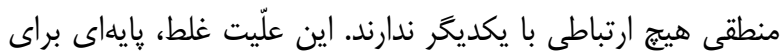

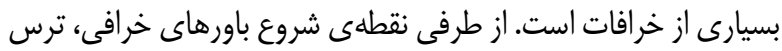

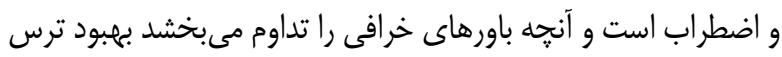

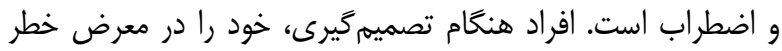

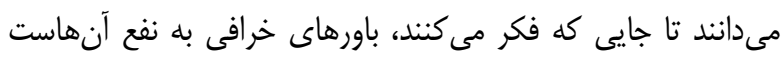

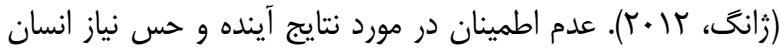
به مهار خود و جهان به شكلى منظم و قابل ييشيينى، تعبيين كنندهى

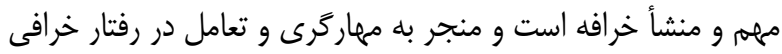

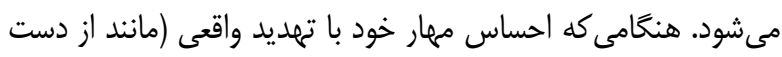
دادن يكى از عزيزان، تحمل يك فاجعلى طبيعى و غيره) كاهش يابدابد،

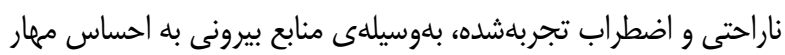

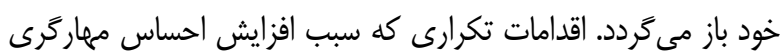

شخصى مىشوند، منجر به باورهاى خرافى ميكر دند (اسييرز، سا • با).

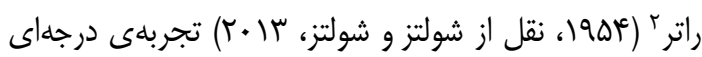

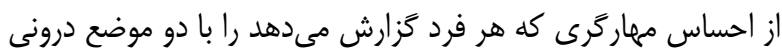

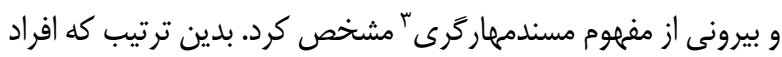

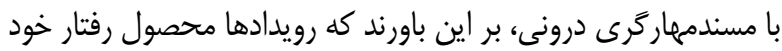

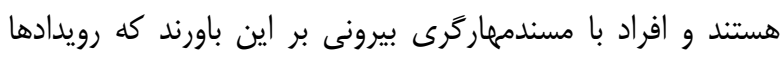
محصول شانس يا نفوذ ديخران بهطور خاص هستند.

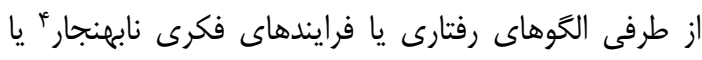

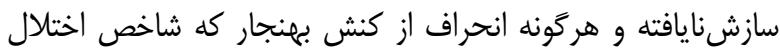

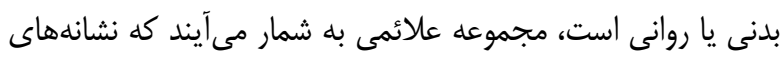

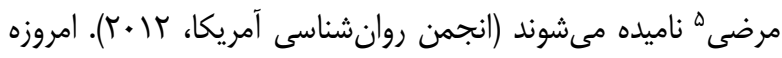

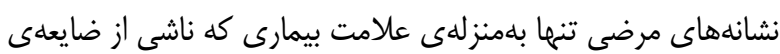

جدول ا. ويزَكىهاى جمعيتشناختى گروه نمونه

\begin{tabular}{|c|c|c|c|c|c|c|c|}
\hline \multicolumn{2}{|c|}{ Sل (n=rr) } & \multicolumn{2}{|c|}{ شاغل (n=9ه) } & \multicolumn{2}{|c|}{ خانهدار (n=1هD) } & & \\
\hline درصد | درد & تعداد & درصد & تعداد & درصد & تعداد & & \\
\hline $99 / 1$ & IQT & $\Delta \Gamma / \Lambda$ & ro & $V \Delta / \Delta$ & IIV & دييلم & \multirow{2}{*}{ تحصيلات } \\
\hline$r . / 9$ & 91 & $r \& / T$ & $r$. & $r \varphi / \Delta$ & r & كارشناسى & \\
\hline$\Delta T / \Gamma$ & 110 & $99 / \pi$ & r & 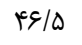 & vr & مجرد مجر & \\
\hline$r_{\Delta} / \mathrm{q}$ & 11. & $r \cdot / \Lambda$ & $r$. & $\Delta T / \Gamma$ & $\wedge$ & متأهل & تأهل \\
\hline $1 / 1$ & r & $r / 1$ & r & $1 / \mu$ & r & مطلقه & \\
\hline & \multicolumn{2}{|c|}{ منطقهى ؟ } & \multicolumn{2}{|c|}{ منطقهى r } & \multicolumn{2}{|c|}{ منطقهى 1} & مناطق شهردارى \\
\hline & \multicolumn{2}{|c|}{$\wedge$} & \multicolumn{2}{|c|}{11} & \multicolumn{2}{|c|}{$\Delta$} & تعداد سراها \\
\hline & \multicolumn{2}{|c|}{$\Lambda \Delta$} & \multicolumn{2}{|c|}{ १人 } & \multicolumn{2}{|c|}{ rV } & تعداد نمونه \\
\hline
\end{tabular}

${ }_{6}^{5}$ psychopathology

${ }^{6}$ Structure

\footnotetext{
${ }^{1}$ Campbell

${ }^{2}$ Acar

${ }^{3}$ Locus of control

${ }^{4}$ abnormality
} 
گَسته گرايى و r شاخص كلى شامل شاخص شدت كلى، شاخص

ناراحتى نشانههاى مثبت و جمع نشانههاى مثبت است.

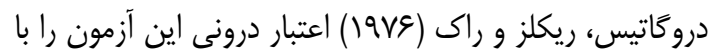

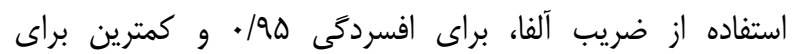

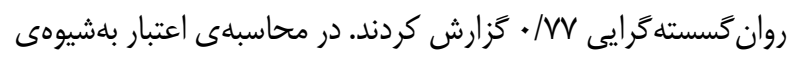

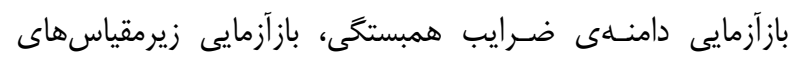

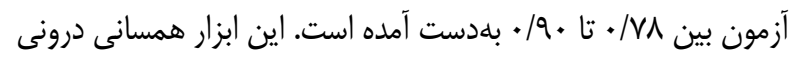

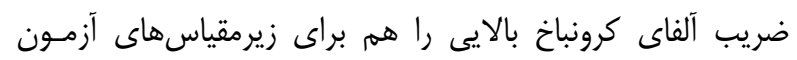

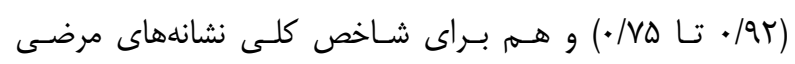

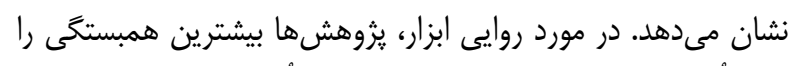

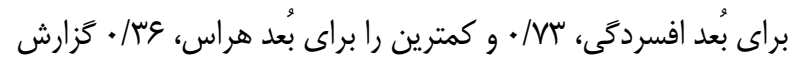

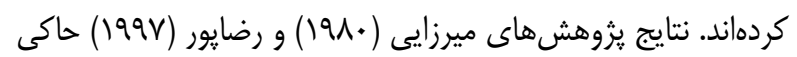

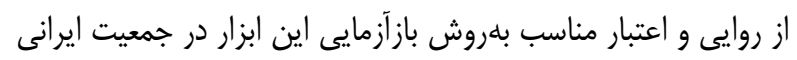

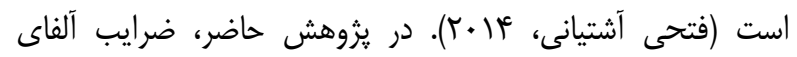

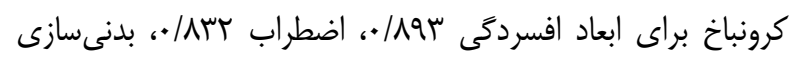

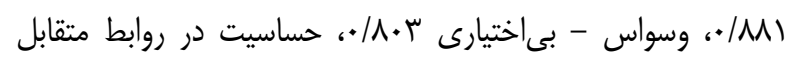

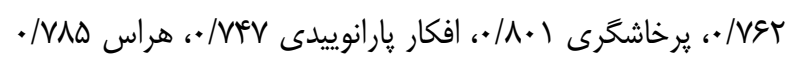

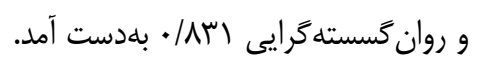

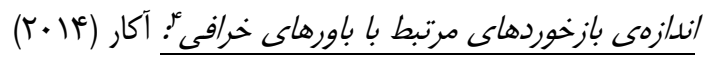

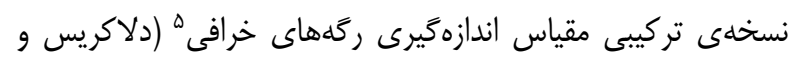

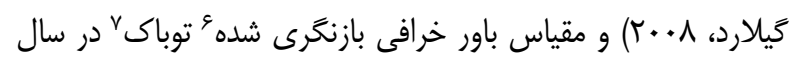

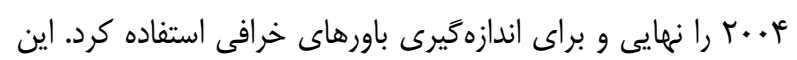

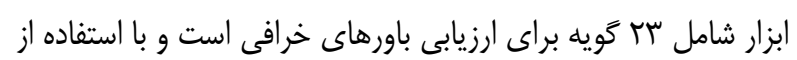

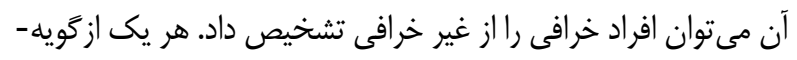
ها در طيف ه درجهاى ليكرت از بهشدت مخالف، مخالف، بى فنظر،

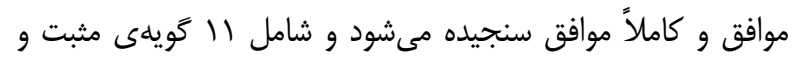

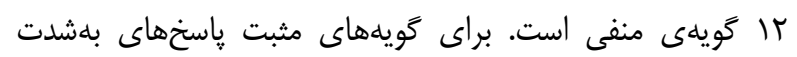

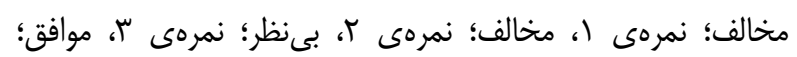

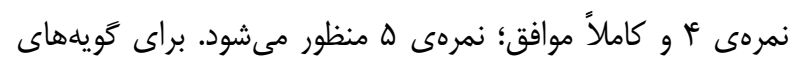

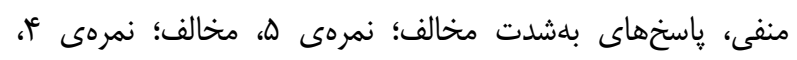

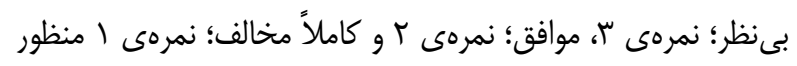
مى شود.

اعتبار درونى با استفاده از ضريب آلفاى كرونباخ، عو/ • گزارش

شده است. توان مقياس، آزمون شده است و با تحليل عاملى قابليت

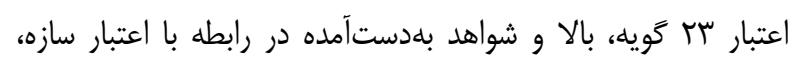
مناسب هستند. ضريب اطمينان آلفاى كرونباخ كه انسجام داخلى سب إنبا

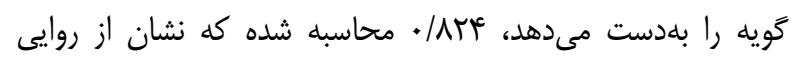

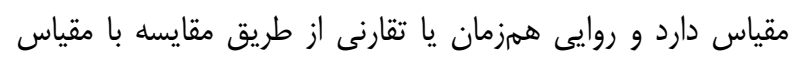

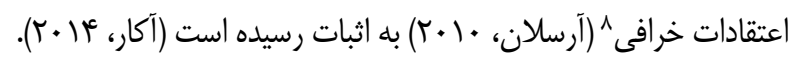

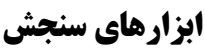

مقياس درونى بودن، افراد قدرتمند و ثانس ': لونسون ' (19VT) بdمنظور مشخص كردن نوع مسندمهارگرى در بزرگسالان با سه

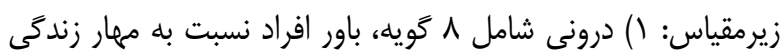

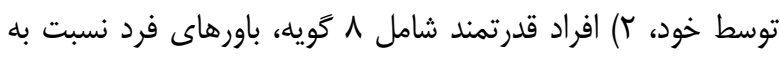

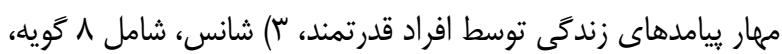

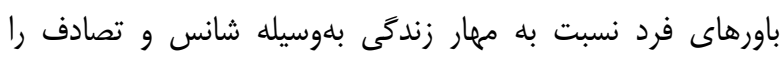

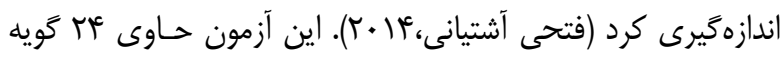

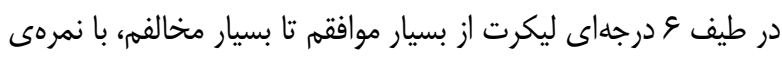

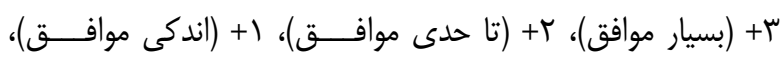

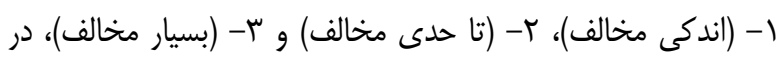
سه زيرمقياس درونى بودن، شانس و افراد قدرتمند است.

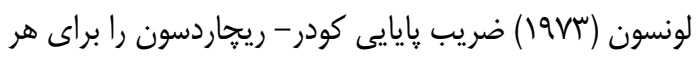

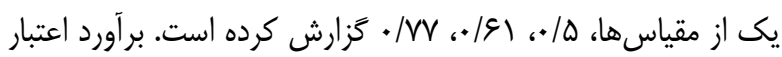

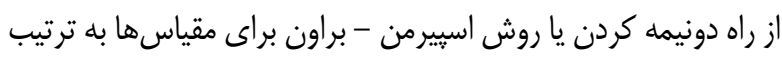

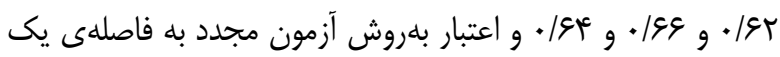

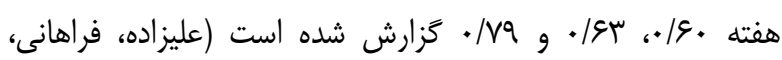

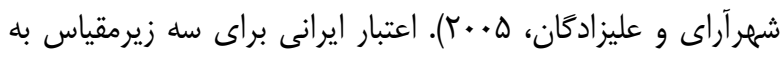

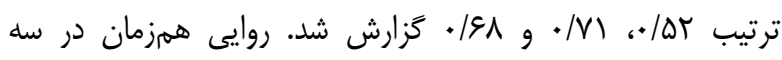
زيرمقياس از طريق مقايسه با مقياس درونى و بيرونى راتر و مقياس

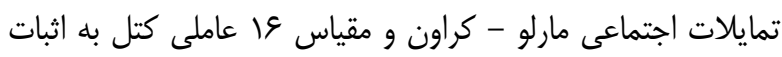
رسيده است. در يزوهش حاضر، ضريب آلفاى كرونباخ در زيرمقياس

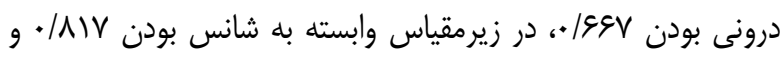

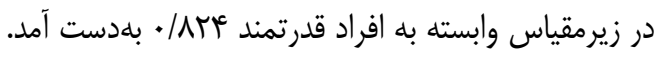

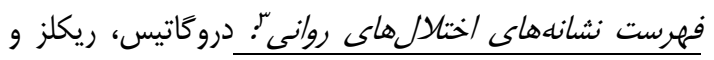

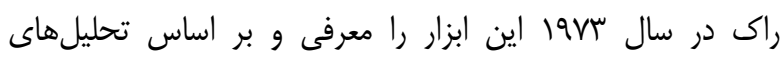
روانسنجى و تجربههاى بالينى مورد تجديدنظر قرار دادند و سرانجام

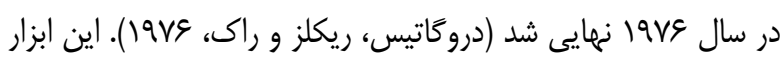

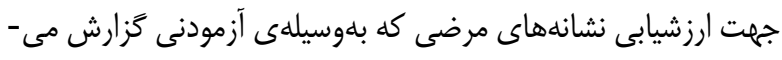

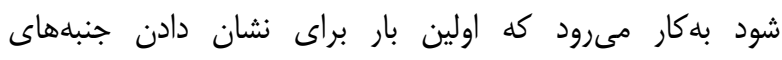
روانشناختى بيماران جسمى و روانى طرحريزى شد و با استفاده از آن

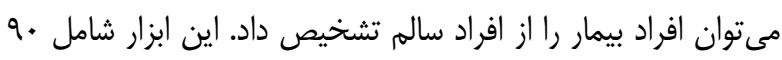

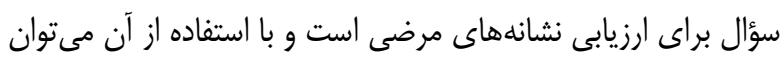

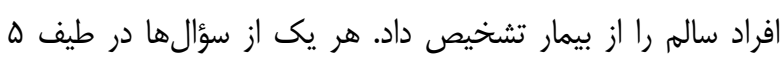
درجهاى ليكرت از نمرهى صفر (هيج) تا جهار (بهشدت) سنجيده شده

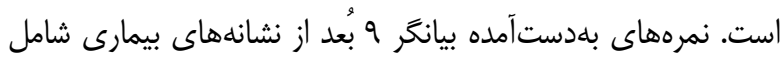

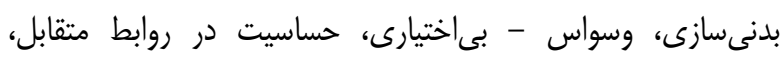

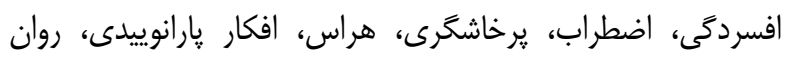

${ }^{5}$ Understanding, defining and measuring the trait of superstition.
${ }^{6}$ A Revised Paranormal Belief Scale
${ }^{7}$ Tobacyk,
${ }^{8}$ Paranormal İnanc Olceğinin TurkceVersiyonunun Geliştirilmes
${ }^{1}$ The Internality, Powerful others and Chance Scale (IPC)

${ }^{2}$ Levenson

${ }^{3}$ Symptom Check List-90-Revised (SCL-90-R)

${ }^{4}$ Measurement of Attitudes Related to the Superstitious Beliefs 
آزمون فرضيههاى يُروهش و بررسى رابطهى باورهاى خرافى با

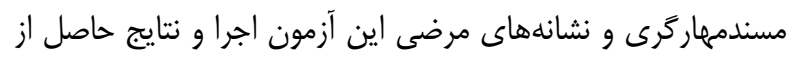

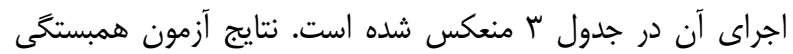

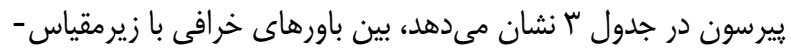

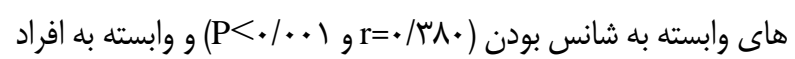

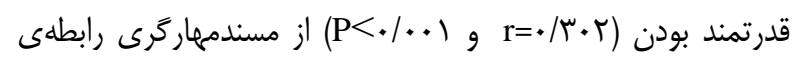

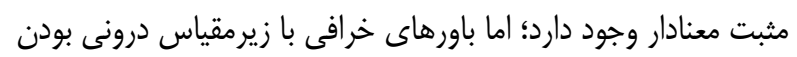

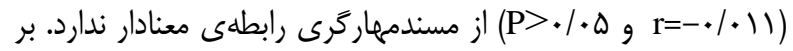

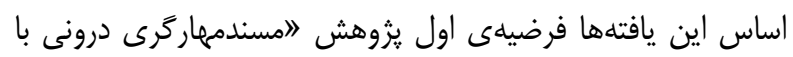

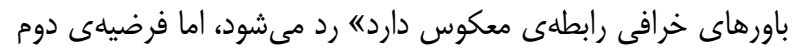

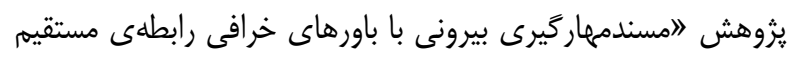

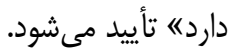

افزون بر آن نتايج نشان مىدهند (جدول بَ) بين باورهاى

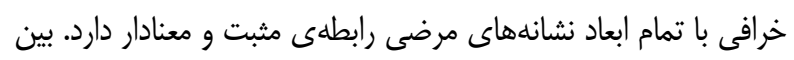

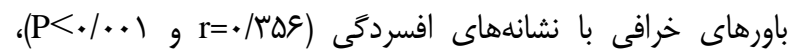

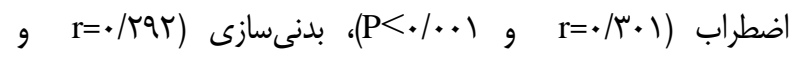
(P<•/.•)

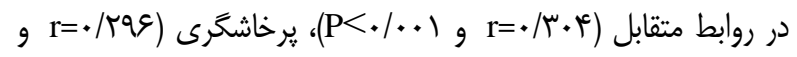

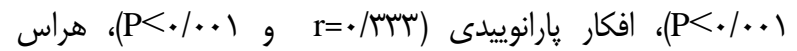

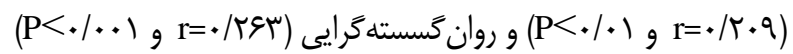
رابطهى مثبت معنادار وجود دارد؛ بنابراين، رابطهى مستقيم نشانههاى

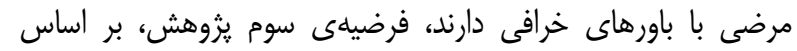

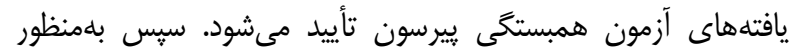

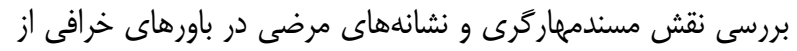

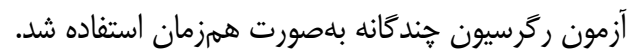

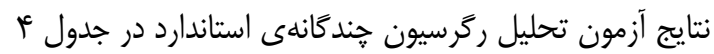

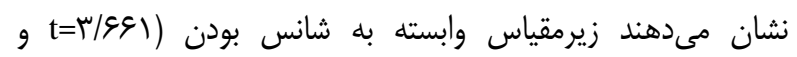

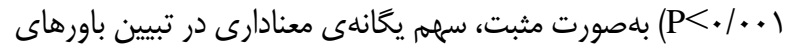

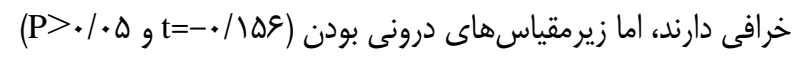

در يزوهش حاضر، ضريب آلفاى كرونباخ براى متغير باورهاى خرافى

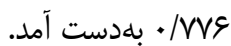

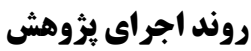

با هماهنكى لازم و كسب اجازه از مسئولان محترم سراهاى

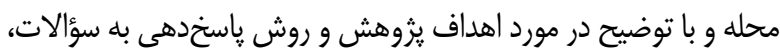

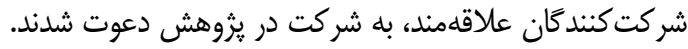

\section{نتايج}

نتايج حاصل از اجراى اندازمى بازخوردهاى مرتبط با باورهاى خرافى، مقياس درونى بودن، افراد قدرتمند و شانس و فهرست

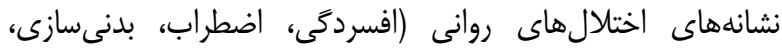

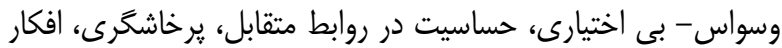

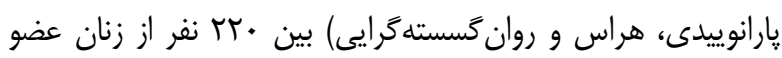
سراى محلههاى تهران بلهصورت ميانكين، انحر اف استاندارد، كمينه و

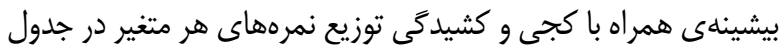

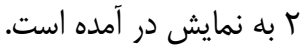
تحليل دادهها در سطح توصيفى با محاسبهى ميانكَين و انحراف

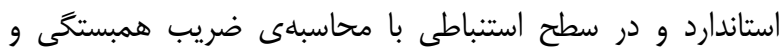

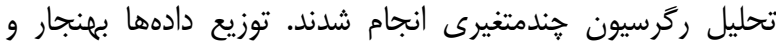

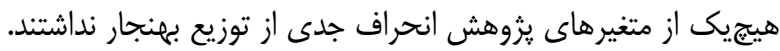
بلهنظور بررسى رابطهى باورهاى خرافى با مسندمهاركرى (درونى إنى

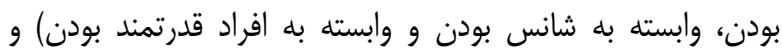

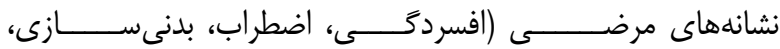

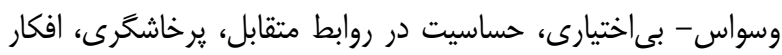

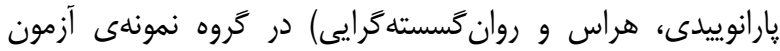

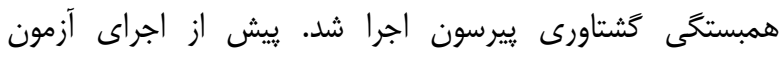

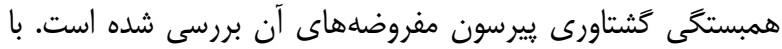

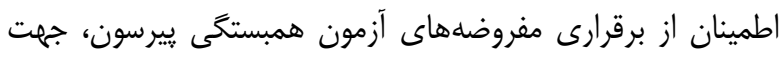

جدول r. خلاصهى يافتهاى توصيفى باورهاى خرافى، مسندمهاركرى و نشانههاى مرضى (•rn=r)

\begin{tabular}{|c|c|c|c|c|c|c|}
\hline كشيدگى & كجى & Max & Min & $\underline{\mathrm{SD}}$ & $\underline{\mathrm{M}}$ & متغيرها \\
\hline$. / \cdot 4 \mid$ &.$- / 9 V^{c}$ & $N$ & Mf & $1 \cdot / V^{e f}$ & gr/W & باورهاى خرافى \\
\hline $1 / v n$ & $-1 / 1 r q$ & iv & 9 & s/avr & r T/q & درونى بودن \\
\hline$-\cdot / \Lambda \cdot r$ & -.1 .99 & is & . & $1 . / 4{ }_{1}$ & $r \pi / . q$ & وابسته به شانس \\
\hline$-\cdot / V T V$ & . TAt & et & . & $1 . / 4 \mathrm{YI}$ & $\mathrm{W} / \mathrm{V}$. & وابسته به افراد قدر تمند \\
\hline.$- / 9 \vee \Delta$ &.$/ 491$ & Tr & . & $11 / 1 \cdot e^{c}$ & $\mathrm{IV} / \mathrm{A}$. & فسردگى \\
\hline$-\cdot$ /QT9 & $.10 \mathrm{~W}$ & 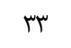 & . & V/qu & $11 / r q$ & ضطراب \\
\hline- . ATQ &.$/ 499$ & et & . & $9 / 944$ & $\mid f / g V$ & بدنى سازى \\
\hline$-\cdot / \mu \cdot V$ & (Fre & ع & . & $V / r I V$ & $\mid F / \Delta S$ & وسواس - بى اختيارى \\
\hline$-\cdot / K+q$ & . IFt & r. & . & s/IVD & $11 / 19$ & حساسيت در روابط متقابل \\
\hline$-\cdot / \Psi V \varepsilon$ & . & r) & . & $\Delta / \cdots V$ & $V / q)$ & برخاشكَرى \\
\hline - & . TYAD & re & . & $F / N G \mid$ & $q / \cdot \Delta$ & فكار يارانوييدى \\
\hline t/4rq & V/DFD & re & · & $F / \Delta S \mid$ & $r / q q$ & هراس \\
\hline$-\cdot / \Delta \mathrm{VV}$ & - IsNi & re & . & S/VIT & $9 / \cdot \Delta$ & 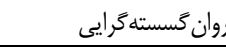 \\
\hline
\end{tabular}


جدول س. ضرايب همبستخى بين مسندمهارگرى، نشانههاى مرضى و باورهاى خرافى

\begin{tabular}{|c|c|c|c|c|c|c|c|c|c|c|c|c|}
\hline$\pi$ & 11 & 1. & $q$ & $\wedge$ & $v$ & 9 & $\Delta$ & r & $r$ & $r$ & 1 & متغيرها \\
\hline & & & & & & & & & & & - & ا-باورهاى خرافى \\
\hline & & & & & & & & & & - &.$- .1 \cdot 11$ & ז-درونى بودن \\
\hline & & & & & & & & & - & $-\cdot \cdot \cdot \cdot r$ & $\cdot /{ }^{\prime} \mu \cdot{ }^{* *}$ & ז-وابسته به شانس \\
\hline & & & & & & & & - & $\cdot / w \cdot{ }^{* *}$ &.$- / . \cdot \Delta$ & $\cdot / r \cdot r^{* *}$ & 'َ-وابسته قدرت \\
\hline & & & & & & & - & . $/$ KY & $\cdot /\left.\Gamma \Lambda\right|^{* *}$ &.$- / r 19^{* *}$ & $\cdot / r \Delta \varphi^{* *}$ & ه-|فسردخى \\
\hline & & & & & & - & $\cdot / \sqrt{ } 99^{* *}$ & ( ) & $\cdot / 499^{* *}$ &.$- / 1 F r^{*}$ & $\cdot / \mu \cdot 1^{* *}$ & و ع-اضطراب \\
\hline & & & & & - & $\cdot / V \omega \cdot{ }^{* *}$ &.$|91|^{* *}$ &.$/ K F \varepsilon^{* *}$ &.$/ \mu V^{* *}$ &.$- / 1 \cdot 1$ &.$/ 4 q r^{* *}$ & V-شكايت جسمانى \\
\hline & & & & - &.$/ 999^{* *}$ & $\cdot / M e^{* *}$ & $\cdot / \Lambda \cdot e^{* *}$ & . & $\cdot / \Gamma \Lambda \Delta^{* *}$ & -.1 .99 & $\cdot / T V D^{* *}$ & ^-وسواس- جبرى \\
\hline & & & - & $\cdot / N{ }^{* *}$ & . $\mid q \pi \mu^{* *}$ & $\cdot / V G .^{* *}$ & $\cdot / v q r^{* \star}$ & $\cdot / \pi \xi q^{* *}$ & $\cdot / / \wedge Q^{* *}$ & $-\cdot / \Lambda r^{* *}$ & $\cdot / r \cdot r^{* *}$ & 9-حساسيت در روابط متقابل \\
\hline & & - &.$/ 9 \Delta r^{* *}$ & $\cdot \mid \Delta \Delta \Lambda^{* *}$ & $\cdot \mid \Delta \Delta \Lambda^{* *}$ & $\cdot 19 \Delta \Lambda^{* *}$ &.$/ \& M f^{* *}$ & $\cdot / K \& 9^{* *}$ & $\cdot / r \Lambda r^{* *}$ &.$- / 1 \cdot 4$ & $\cdot / / 98^{* *}$ & • ا-رخخاشكرى \\
\hline & - & $\left.\cdot|r|\right|^{* *}$ & $.199 . *$ & $.1910^{* *}$ & $\cdot / \Delta N \varepsilon^{* *}$ &. $\mid g<\mu^{* *}$ & $\cdot / V \mid \cdot^{* *}$ & $\cdot / \mu r V^{* *}$ & $\cdot / \mu \lambda r^{* *}$ &.$-|\cdot \Delta|$ & ( ) & 11-|فكار קارانوييدى \\
\hline- & 先 &.$/ F T V^{* *}$ &.$/ g * r^{* *}$ & $\cdot|\Delta S|^{* *}$ & $.1010^{* *}$ & $.199 r^{* \star}$ & $\cdot / Q T \cdot{ }^{* *}$ & . /MFr** & $\cdot / r \Delta V^{* *}$ &.$/ I F$ & $\cdot / r \cdot 9^{* *}$ & זו-ترس مرضى \\
\hline $.19 \vee \Delta^{* *}$ &.$|q W|^{* *}$ & . $/$ \& $9^{* *}$ & $\cdot / V T \Lambda^{* *}$ & $\cdot / V \Delta \Delta^{* *}$ & $\cdot|\& \Delta|^{\star \star}$ & $\cdot / \operatorname{vav}^{* *}$ & $\cdot / V \Lambda r^{* *}$ & $\cdot / \mu Y q^{* *}$ & $\cdot / \Gamma \Delta r^{* *}$ & $-\cdot / r \cdot \Lambda^{* *}$ & $\cdot / R g \mu^{* *}$ & سا - روان كسستهكرايى \\
\hline
\end{tabular}

$* * \mathrm{P}<\cdot / . \cdot 1 . * \mathrm{P}<\cdot / \cdot \Delta$

اساس ضريب تعيين بهدستأمده (R ) نشانههاى مرضى ها درصد

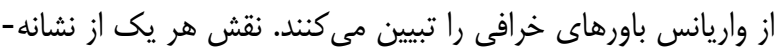

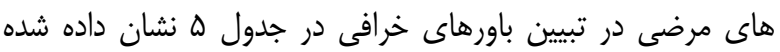

است.

نتايج آزمون تحليل رگرسيون هندكانهى استاندارد در جدول ه نشان

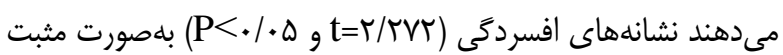
سهم يخانه و معنادارى در تبيين باورهاى خرافى دارند، اما ساير

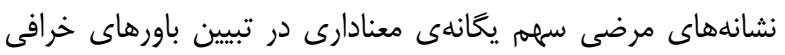

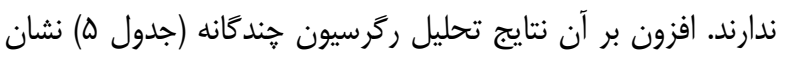

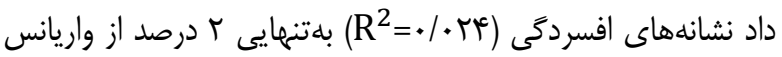

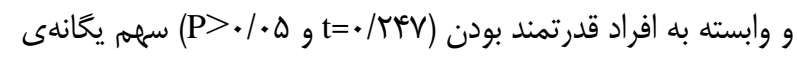
معنادارى در تبيين باورهاى خرافى ندارند. افزون بر آن نتايج تحليل

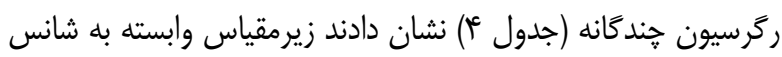

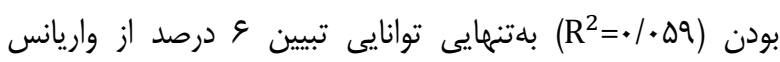
باورهاى خرافى را بهصورت مثبت دارد.

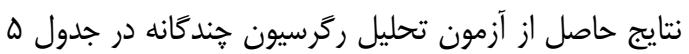
براى ييشبينى باورهاى خرافى با نشانههاى مرضى (F=F/TF

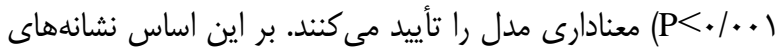
مرضى ييشبينى كننده معنادارى براى باورهاى خرافى هستند. بر مدر

جدول fا. ضرايب رگرسيون باورهاى خرافى با مسندمهارگرى

\begin{tabular}{|c|c|c|c|c|c|}
\hline $\mathrm{R}^{2}$ & $\mathrm{~T}$ & $\beta$ & $\underline{\text { SEB }}$ & B & متغيرهاى ييشبين \\
\hline & 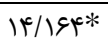 & & r/Ar & $\Delta F / T \Delta V$ & مقدار ثابت \\
\hline $.1 \%$ & $-\cdot / 1 \Delta \xi$ & $-\cdot 1 \cdot 1 \cdot$ & .1 .98 &.$- \cdot 1 \cdot 10$ & درونى بودن \\
\hline .1 .09 & r/وql* & ום וא/. & $.11 . r$ &.$/ T V T$ & وابسته به شانس \\
\hline.$/ \ldots$ & . MFV &.$/ . t r F$ &.$/ 1 \cdot 1$ & $.1 . r \Delta$ & وابسته به افراد قدرتمند \\
\hline
\end{tabular}

$* \mathrm{P}<\cdot \mid \cdot \cdot 1$

\begin{tabular}{|c|c|c|c|c|c|}
\hline $\mathrm{R}^{2}$ & $\mathrm{~T}$ & $\beta$ & $\underline{\text { SEB }}$ & B & متغيرهاى بيشبين \\
\hline & 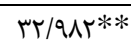 & & $1 / 8 \wedge \Delta$ & $\Delta \omega / \Delta S$. & مقدار ثابت \\
\hline $.1 \cdot T^{2}$ & $r / r V T *$ & . & ./IMr & 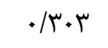 & افسردگى \\
\hline.$/ \cdots$ & . TAR & $.1 . \mu F$ &.$/ M A F$ & $.1 \cdot \mathrm{PV}^{2}$ & اضطراب \\
\hline r... & $\cdot / V \Delta V$ & $.1 \cdot \mathrm{VV}$ &.$/ 114$ &.$/ \cdot N$ & بدنى سازى \\
\hline . & $-\cdot / \Lambda \mu \wedge$ & $-\cdot / 1 \cdot r$ &.$/ 1 \Lambda$. & $-\cdot|| \Delta \mid$ & وسواس- بى اختيارى \\
\hline$\cdot 1 \cdots$ &.$- / 198$ &.$- / \cdot r \Delta$ & $. / T / \Lambda$ & س ש. & حساسيت در روابط متقابل \\
\hline.$/ \cdot r$ &.$|90|$ & .1 .90 &.$/ T I f$ &.$/ 14$ & يرخاشگرى \\
\hline $.1+1$ & $1 / \mp M$ &.$/ 191$ &.$/ r m q$ & . & افكار پارانوييدى \\
\hline $.1 \cdot r$ & $.19 \vee 9$ & .1 .90 & . /TTV &.$/ N a F^{2}$ & هراس \\
\hline$\cdot 1 \cdot v$ & سותות & $-\cdot / 1 \otimes \wedge$ & $\cdot / 4 \cdot 1$ & $-\cdot / T \Delta T$ & روان گَستهـرَ ايى \\
\hline
\end{tabular}




\begin{tabular}{|c|c|c|c|c|c|}
\hline $\mathrm{R}^{2}$ & $\mathrm{~T}$ & $\beta$ & $\underline{\text { SEB }}$ & $\mathrm{B}$ & متغيرهاى ييشبين \\
\hline & $I T / T \Delta V^{* *}$ & & $r / \cdot \Delta V$ & $|q q / v m|$ & مقدار ثابت \\
\hline $.1 \cdot 1$ & - /DTD &.$/ \cdot m{ }^{2}$ &.$/ 1$. & س & درونى بودن \\
\hline |. & $r / \Delta \wedge 9^{*}$ &.$/ 4 \& 9$ & $\cdot / 1 \cdot v$ & $\cdot / T V V$ & وابسته به شانس \\
\hline$\cdot 1 \ldots$ & - & $.1 \cdot 11$ & $\cdot 11 \cdot{ }^{2}$ & $.1 \cdot 11$ & وابسته به افراد قدرتمند \\
\hline $.1 \cdot t r$ & $r / T V \Lambda^{*}$ & ( ) & ( & (r/T & افسردگى \\
\hline.$/ \ldots$ & $-\cdot / 1 \cdot c^{4}$ & $-.1 \cdot 1 f^{f}$ &.$/ 189$ &.- .1 .19 & اضطراب \\
\hline 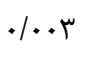 & $\cdot / \Lambda F \Delta$ & $\cdot / \cdot \lambda F$ &.$/ 111$ & .1 .94 & بدنى سازى \\
\hline$\cdot / \cdot V$ & - &.$- / 148$ &.$/ 1 V 8$ & $-\cdot / M I F$ & وسواس - بى اختيارى \\
\hline $.1 \cdots 1$ & | ( & $-.1 \cdot+4$ & שוT/R & $-\cdot / \cdot v V$ & حساسيت در روابط متقابل \\
\hline $.1 \ldots$ & $\cdot|r q|$ & $.1 . r q$ & $\cdot|4| \mid$ & .1 .91 & يرخاشگرى \\
\hline$\cdot 1 \cdot \cdot v$ & $1 / 119$ & . MTE & (TMD & $\cdot / T \Lambda$ & افكار يارانوييدى \\
\hline 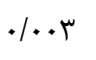 & $\cdot / V^{4}$ & $\cdot / \cdot v$ & ./TME &.$/ 198$ & هراس \\
\hline$\cdot 1 \cdots \infty$ & سץ./1- & - & $\cdot / T \cdot \Delta$ & $-\cdot / 411$ & روان گَستسهَ ايى \\
\hline
\end{tabular}

$* * \mathrm{P}<\cdot / \cdot+1 . * \mathrm{P}<\cdot / \cdot \Delta$

معنادار بين مسندمهارگ گى بيرونى و باورهاى خرافى و همجنين تأييد

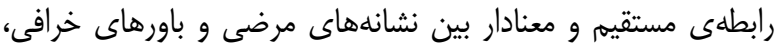
فرضيههاى دوم و سوم يزوهش تأييد شد. افزون بر اين، نتايج نشان دادند مسندمهارگرى بلهتنهايى درصد و زيرمقياس وابسته به شانس بودن بلهصورت مثبت سهرانه يكانهى معنادارى در تبيين باورهاى خرافى دارد، اما زيرمقياسهاى

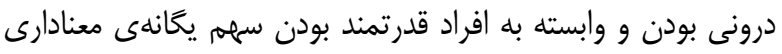

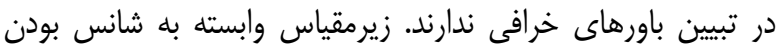

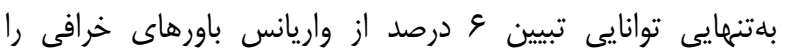

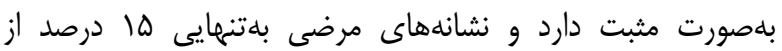

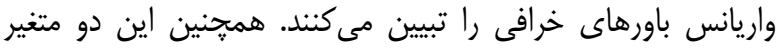

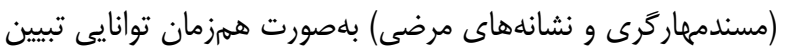

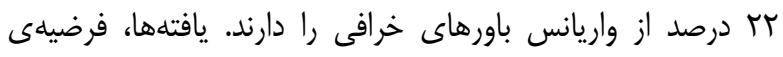

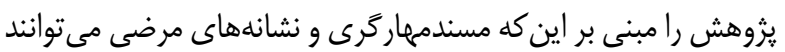
باورهاى خرافى را ييشينى كنند تأيبد مى كنند.

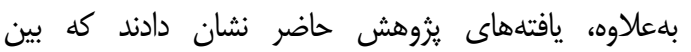

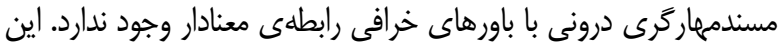

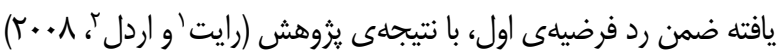

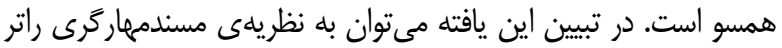

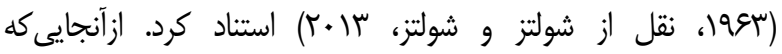

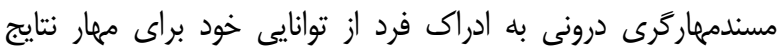

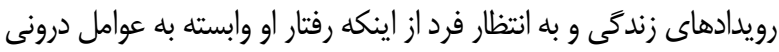
مانند رفتار خود و خصوصيات شخصى خود اشاره دارد؛ لذا افرادى كه دار اراى

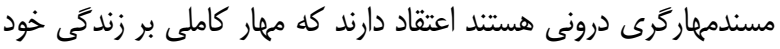
داشته و مطابق با همين باور رفتار مى كنند. ديكر يافتهى يزوهش حاضر نشان داد كه بين باورهاى خرافى
باورهاى خرافى را بهصورت مثبت تبيين مى كند. اين يافتهها نشان

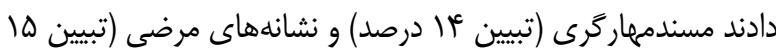
درصد) توانايى ييشبينى باورهاى خرافى را دارند.

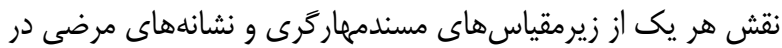
تبيين باورهاى خرافى در جدول \& بررسى شده است. نتايج نشان دادند

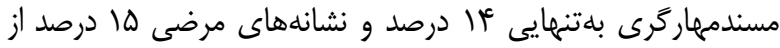

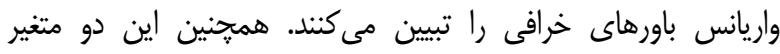

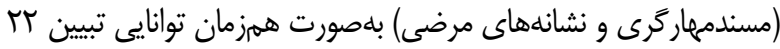

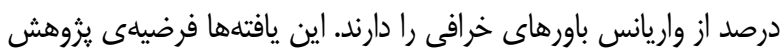

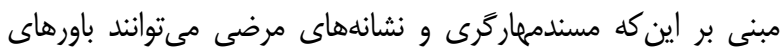
خرافى را ييشبينى كنند را تأييد مى كنند.

\section{بحث و نتيجه}

هدف يزوهش حاضر، ارزيابى رابطهى مسندمهارگرى،

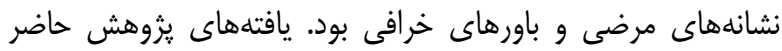

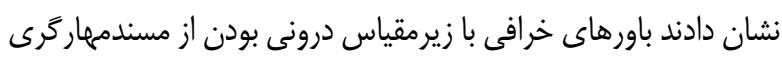

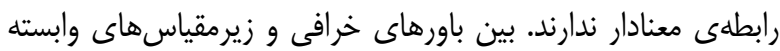

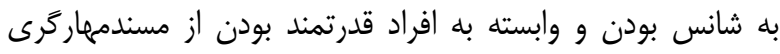

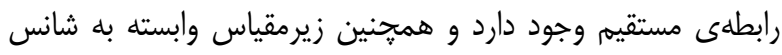
بودن بلصورت مثبت سهم يحانهى معنادارى در تبيين باورهاى خرافى

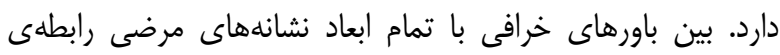

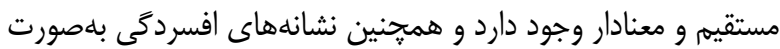

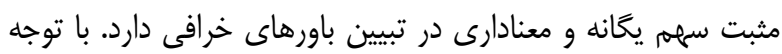

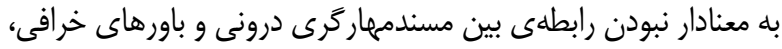

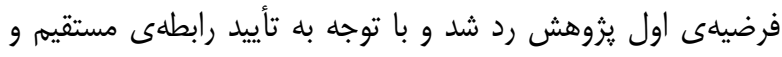


مرضى و انتقال را ازلحاظ ماهيت يكسان و داراى مبناو فرايند انحلال

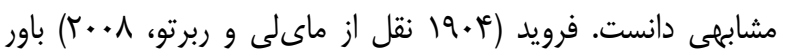

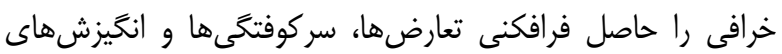

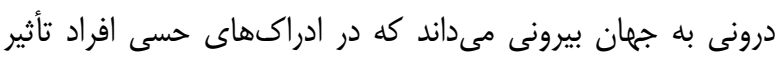

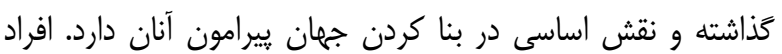

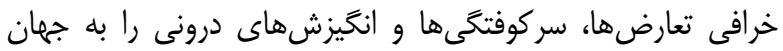

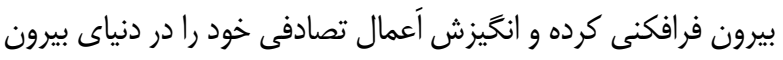
جستجو كرده، تصادفها و اتفاقها را خرافهوار تعبير مى كنند.

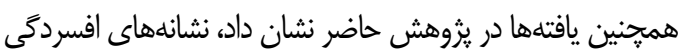

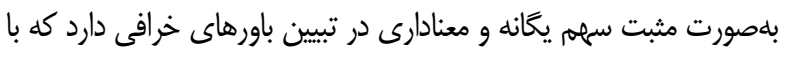

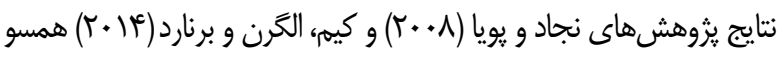

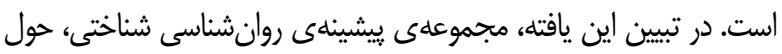

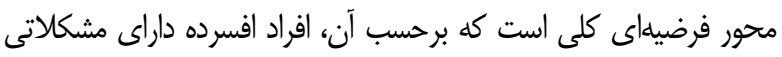

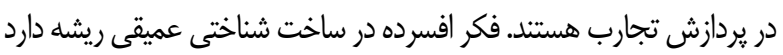

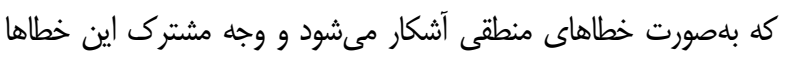

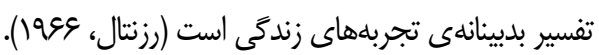

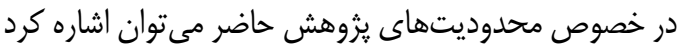

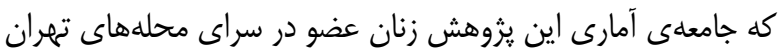

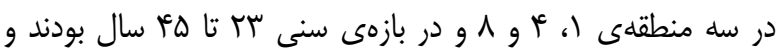

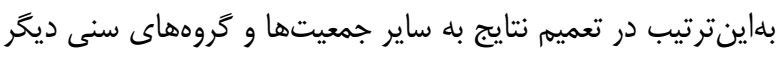

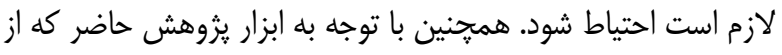

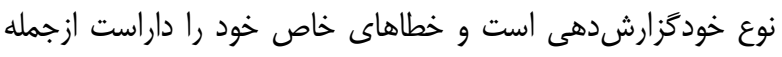

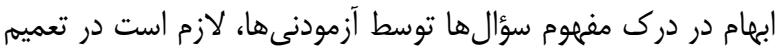

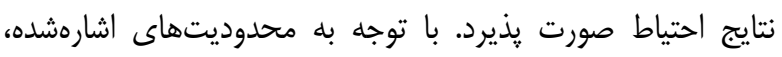

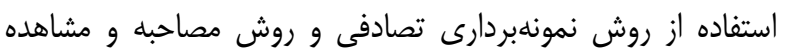

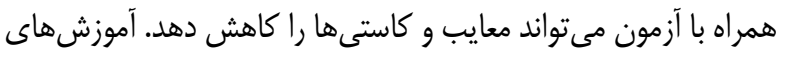

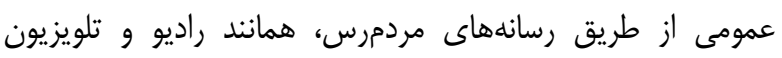

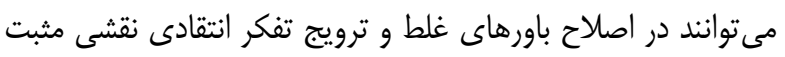

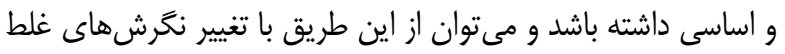
بركَرفته از فرهنگ به يويايى و رشد جامعه دست يافت.

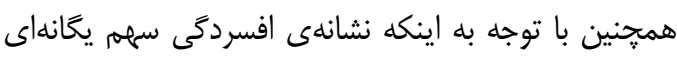

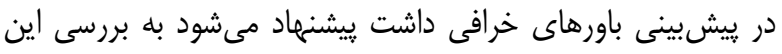

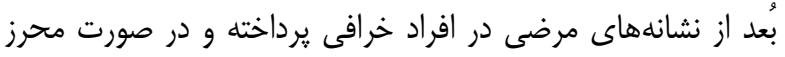

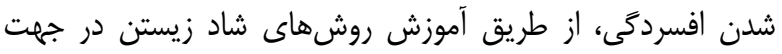

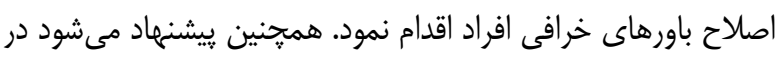

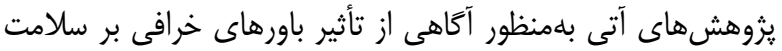

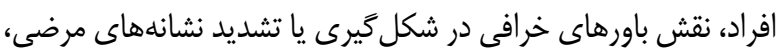
مورد مطالعه و يزوهش قرار كيرد.
و مسندمهارگرى بيرونى رابطهى مستقيم معنادارى وجود دارد.

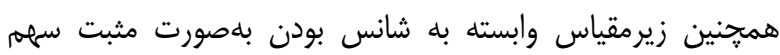
يحانهى معنادارى در تبيين باورهاى خر افى دارد. اين يافته ضمن تأييد

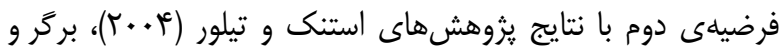

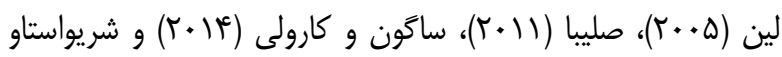

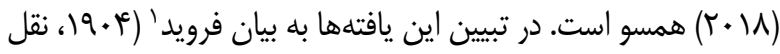

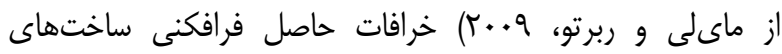
شخصيت به جهان بيرون است كه در ادراك حسى افراد تأثير كذاشته

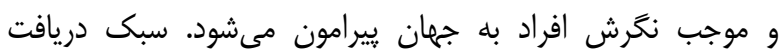

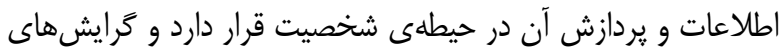

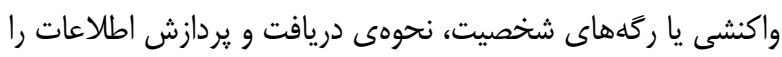

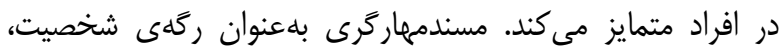

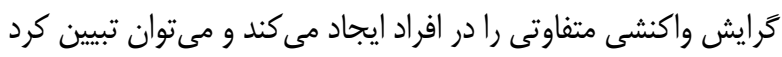

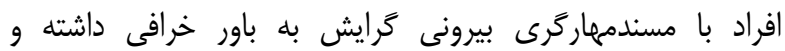
مسندمهاركَى بيرونى ييشيبنى كنندهى باورهاى خرافى است.

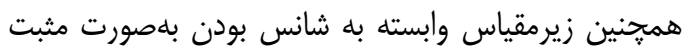

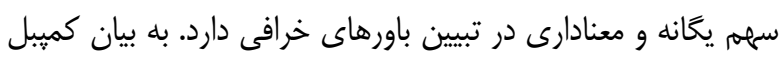

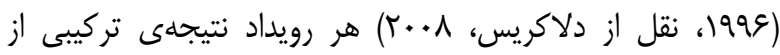
نيروهاى قابلمهار و غيرقابل فمهار است و منشأ خرافه، احساس نياز نياز

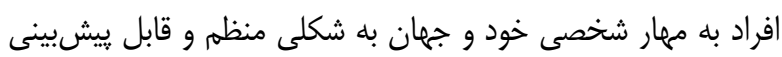

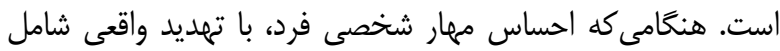

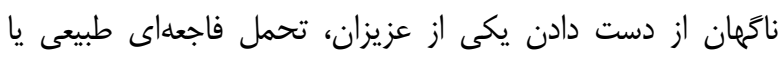
مشاركت در بازىهاى وابسته به شانس تهرئ تهديد شود، ناراحتى و

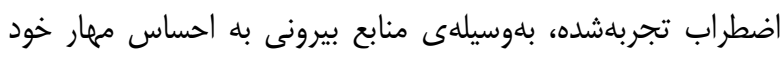
بازمى گردد. در افراد خرافى، عدم اطمينان در مورد نتايج آينده و تمايل

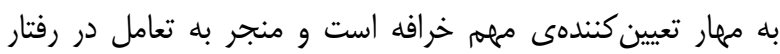

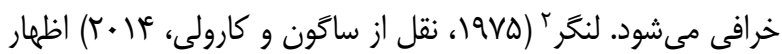

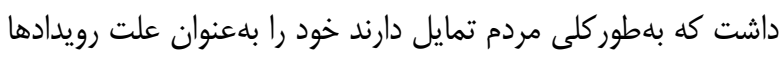

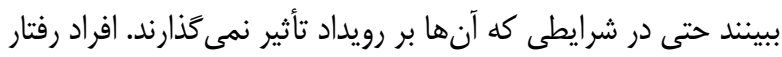

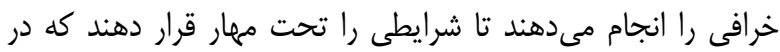

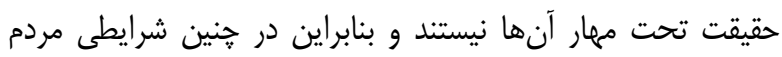

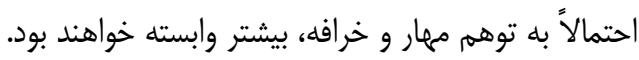

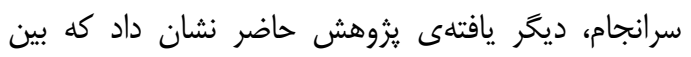

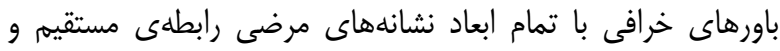

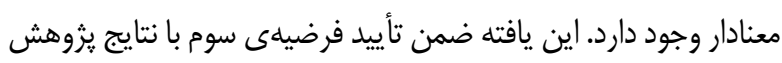

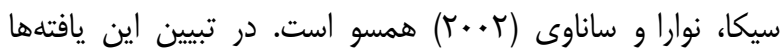

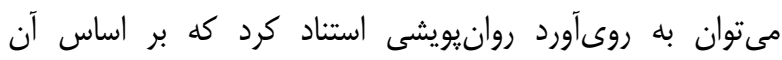

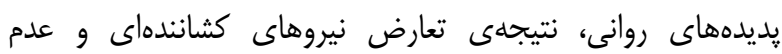

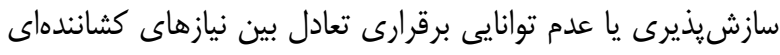

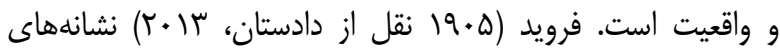

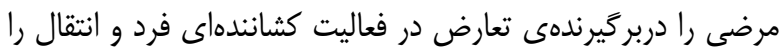

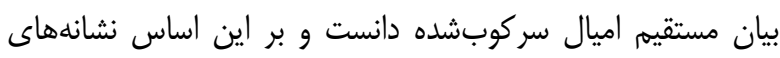




\section{Reference}

Acar, T. (2014). The Struggle of Measurement of Attitudes Related to the Superstitious Beliefs. Journal of Education and Practice, 5(21), 2221735.

Alizadeh, T., Farahani, M., Shahraray, M. \& Alizadegan, Sh. (2005). The relationship between self-esteem and control source with infertility stress in infertile men and women. Journal of Fertility and Infertility, 194-204. [In Persian, 1384]

American Psychiatric Association (2014). Diagnostic and Statistical Manual of Mental Disorders (DSM5). Translated by F. Reza'i, and others. Tehran: Arjmand Publications. [In Persian, 1393]

American Psychological Association (2012). Descriptive culture of the American Psychological Association. (APA) Editor G. R. R. Vandbus. Tehran: Aras Publications. [In Persian, 1391]

Arslan, M. (2010). Paranormal İnanc Olceğinin Turkce Versiyonunun Geliştirilmesi: Gecerlik ve Guvenirlik. Calışması, İ.Ü. İlahiyat Fakültesi Dergis, 1(2), 23-40.

Barrett, J. L. (2000). Exploring the Natural Foundations of Religion. Trends in Cognitive Science, 4 (1), 29-34. [DOI:10.1016/S1364-6613(99)01419-9]

Burger, J. M., \& Lynn, A. L. (2005). Superstitious behavior among American and Japanese professional baseball players. Basic and Applied Social Psychology, 27, 71-76. [DOI:10.1207/ s15324834basp2701_7]

Canino, G., Bird, H. R., Rubio-Stipec, M., \& Bravo, M. (1995). Child psychiatric epidemiology: What we have learned and what we need to learn. Int J Meth Psychiatr Res, 5(2), 79-92.

Dadsetan, P. (2013). Morbid psychology from childhood to adulthood. Tehran: Samt Publications. [In Persian, 1392]

Dadsetan, P. (2014) Excerpts from the largest systems of developmental psychology. Tehran Samt Publications. [In Persian, 1393]

Delacroix, E. \& Guillard, V. (2008). Understanding, Defining and measuring the trait of superstition, Paris: Dauphine University.

Derogatis, L. R., Rickels, K., \& Rock, A. (1976). The SCL-90 and the MMPI: A step in validation of a new self-report scale. Br J Psychiatry, 128, 280-9. [DOI:10.1192/bjp.128.3.280] [PMid:1252693]

Fathi Asaghiani, A. (2014). Psychological tests, personality evaluation and mental health. Tehran: Besat Publications. [In Persian, 1393]

Gershman, B. (2015). The economic origins of the evil eye belief. Journal of Economic Behavior \& Organization, 110, 119-144. [DOI:10.1016/j. jebo.2014.12.002]

Jung, C. G. (2012). The Collected Works of C.G. Jung, Princeton University Press, Princeton, NJ.
Kasherwa, A. C., \& Twikirize, J. M. (2018). Ritualistic child sexual abuse in post-conflict Eastern DRC: Factors associated with the phenomenon and implications for social work, 8, 74-81. [DOI:10. 1016/j.chiabu.2018.04.012] [PMid:29723701]

Kim, J., Ahlgren, M., \& Bernhard, B. (2014). The mediating effect of depression between superstitious beliefs and problem gambling: a cross-cultural study of Chinese and Caucasians residing in the United States. Journal of Gambling Issues, 29, 1-25. [DOI:10.4309/jgi.2014.29.10]

Langer, E. J. (1975). The illusion control. Journal of Personality and Social Psychology, 32,311-328. [DOI:10.1037/0022-3514.32.2.311]

Levenson, H. (1973). Multidimensional locus of control in psychiatric patients. Journal of consulting and clinical psychology, 41(3), 397. [DOI:10.1037/ h0035357] [PMid:4803272]

Miley, R., \& Reberto, P. (2008). Construction, phenomenon and transformation of personality. Translation: Mansour. M. Tehran: Samt Publications. [In Persian, 1387]

Nejad, A. G., \& Pouya, F. (2008). Relationship between superstitious beliefs and anxiety, depression in Iran. European Psychiatry, 23, S374. [DOI: 10.1016/j.eurpsy.2008.01.1294]

Rosenthal, R. (1966). Experimenter effects in behavioral research. East Norwalk, CT, US: Appleton-Century-Crofts.

Rutter, J. B. (1954). Generalized expectancies of Internal versus External control of reinforcements. Psychological Monographs, 80, 609-.

Sagone, E., \& Carole, M. E. (2014). Locus of control and beliefs about superstition and luck in adolescents: what's their Relationship? Procediasocial and behavioural sciences, 140, 318-323. [DOI:10.1016/j.sbspro.2014.04.427]

Saliba, O. (2011). Superstition, religiosity, \& locus of control: the beliefs of Maltese University students Bachelor's thesis, University of Malta.

Schippers, M. C. \& Lange P. A. M. (2006), The Psychological Benefits of Superstitious Rituals in Top Sport: A Study among Top sportspersons, Journal of Applied Social Psychology, 36, 10, 2532 - 2553. [DOI : 10. $1111 /$ j. 0021 - 9029. 2006.00116.x]

Schultz, D., \& Schultz, A. (2013). Personality Theories. Translated by Y. Seyed Mohammadi. Tehran: Virayesh Publications. [In Persian, 1392]

Schumaker, R. A., \& Lomax, R. J. (2009). Introduction to Structural Equation Modeling. Translation: Ghasemi. Tehran: jamee shenasan Publication. [In Persian, 1388]

Shahsavari, A., \& Bayat, M. (2012). Study of tendency to superstition in physical diseases referred to nontherapeutic people. Journal of Nursing 
Development in Health, 3, 55-66. [In Persian, 1391]

Shrivastav, M. (2017). Study on Self-Confidence Contributing to Superstition Behavior. India: Haridwar. [DOI: 10. 29121/ granthaalayah. v5. i7. 2017.2128]

Shrivastav, M. (2018). Study on Locus of Control Contributing to Superstition Behavior. International Journal of Research - Granthaalayah. [DOI: 10. 29121/ granthaalayah. v6.i5.2018.1446]

Sica, C., Novara, C., \& Sanavio. E. (2002). Culture and psychopathology: Superstition and obsessive compulsive cognition and symptoms in a nonclinical Italian sample. Personality and Individual
Differences, 32, 1001-1012. [DOI: 10.1016 / S0191 - 8869 (01) 00104-0]

Spears, L. N. (2013). An Examination of Magical Beliefs as Peredictor of Obzersive Compalsive Symptom Dimonens. University of Kansas in partial fulfillment of the requirement.

Stanke, A., \& Taylor, M. (2004). Religiosity, locus of control, and superstitious belief. UW-L Journal of Undergraduate Research, 11, 1-5.

Wright, P. B., \& Erdal, K. J. (2008). Sport superstition as a function of skill level and task difficulty.Journal of sport behavior, 31(2), 187199. 